\title{
Trigeminal nerve thickening in chronic inflammatory demyelinating polyneuropathy
}

Hipertrofia dos nervos trigêmios em polineuropatia inflamatória desmielinizante crônica Bruno Fukelmann Guedes, Rubens Gisbert Cury

A 21-year-old male presented with 4 years of progressive arm and leg weakness, wasting, areflexia, length-dependent sensory loss, and difficulty walking. Electrodiagnostic studies met diagnostic criteria for chronic inflammatory demyelinating polyneuropathy $(\mathrm{CIDP})^{1}$. CSF analysis showed elevated total protein. MRI of the head (Figures
1 and 2) and spinal cord (Figure 3) showed spinal root hypertrophy and enhancement as well as thickening and enhancement of the trigeminal nerves. The most distal branches of the trigeminal nerve, such as the supraorbital ${ }^{2}$, frontal or inferior alveolar nerves, are seldom portrayed in reports of CIDP.
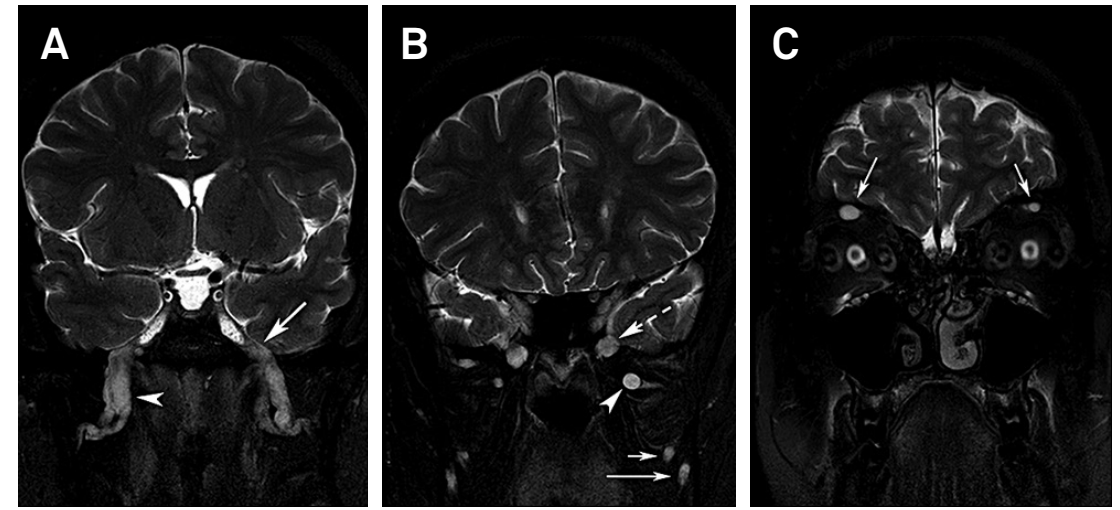

Figure 1. T2-weighted imaging demonstrating enlargement of trigeminal nerve divisions and distal branches in coronal sections. (A): maxillary nerve (arrow) and mandibular nerve (arrowhead); (B): maxillary nerve (dashed arrow) and mandibular nerve branches: buccal nerve (arrowhead), lingual nerve (short arrow) and inferior alveolar nerve (long arrow); (C): Frontal nerves (ophthalmic nerve branches; arrows).
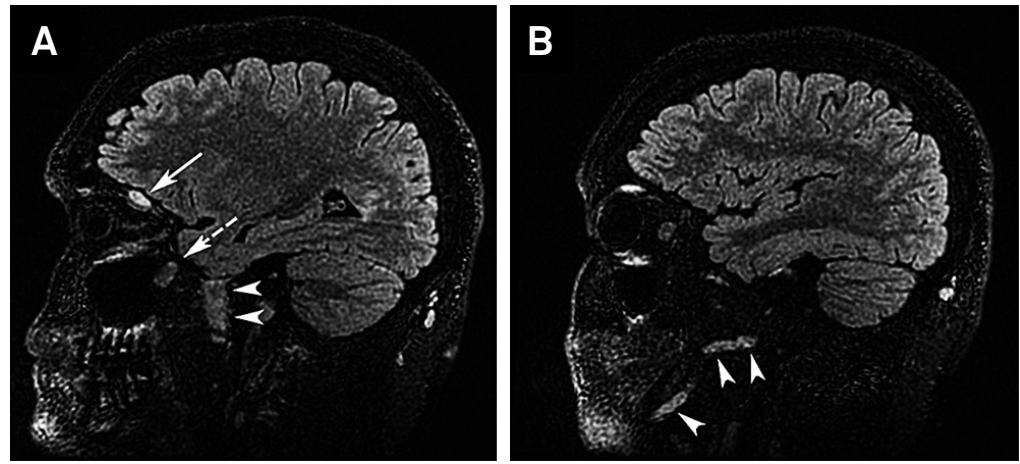

Figure 2. Parassagital FLAIR sections of the head. (A): frontal nerve (ophthalmic nerve branch; arrow), maxillary nerve (dashed arrow) and mandibular nerve (arrowheads). (B): Inferior alveolar nerve (mandibular nerve branch; arrowheads). 

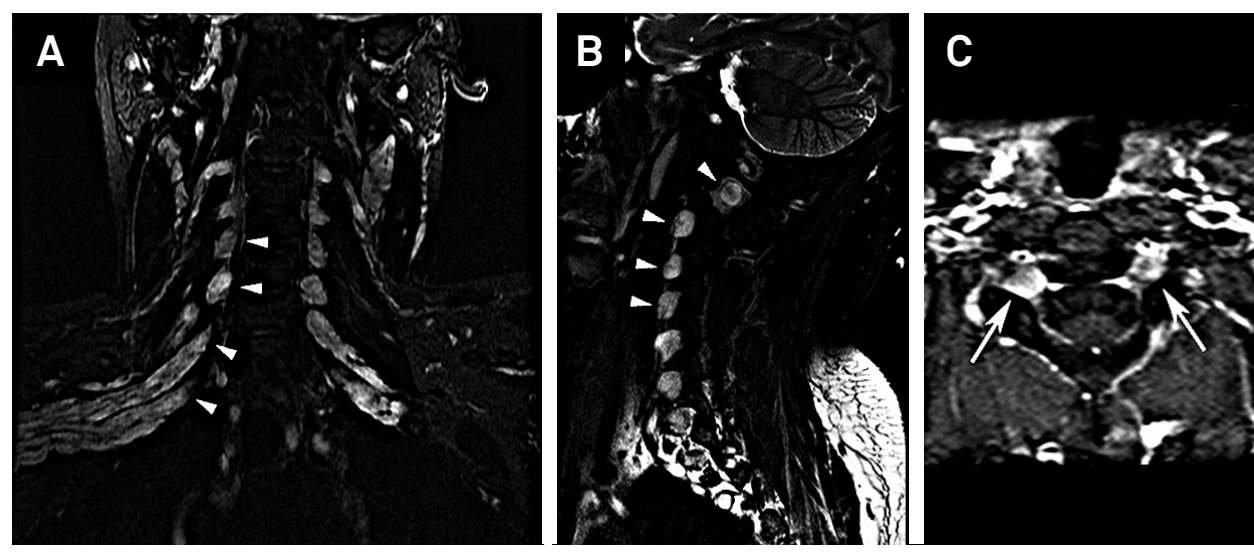

Figure 3. Cervical root hypertrophy. Coronal (A) and sagittal (B) STIR imaging of the cervical spine show root hypertrophy (arrowheads). Spectral Adiabatic Inversion Recovery (SPAIR) imaging (C) demonstrates the above-mentioned root hypertrophy in this axial section (arrows).

\section{References}

1. Van den Bergh PY, Hadden RD, Bouche P, Cornblath DR, Hahn A, Illa I et al. European Federation of Neurological Societies/Peripheral Nerve Society guideline on management of chronic inflammatory demyelinating polyradiculoneuropathy: report of a joint task force of the European Federation of Neurological Societies and the Peripheral Nerve Society-First Revision. Eur J Neurol. 2010;17(3):356-63.

http:dx.doi.org/10.1111/j.1468-1331.2009.02930.x
2. Okuzumi A, Hatano T, Nakahara T, Yokoyama K, Hattori N. Ophthalmic nerve hypertrophy in chronic inflammatory demyelinating polyradiculoneuropathy. Neurology. 2014;82(17):1566-7. http://dx.doi.org/10.1212/WNL.0000000000000362 